\title{
Fungsi Sosial dan Transendental Tradisi Lisan Dero-Sagi Suku Bajawa-Ngada, Flores, Nusa Tenggara Timur
}

\author{
Sastri Sunarti \\ Badan Pengembangan dan Pembinaan Bahasa
}

\begin{abstract}
Abstrak
Keterpingiran dan kehilangan tradisi lisan di Indonesia pada dekade terakhir menjadi isu yang kerap dikeluhkan oleh para peneliti di bidang tradisi lisan. Namun, dalam tulisan ini saya mencoba memperlihatkan bagaimana Dero-Sagi (tradisi lisan) masyarakat Ngada, Bajawa, Flores, NTT bertahan dalam gempuran globalisasi dan permarginalan tradisi lokal. Ritual DeroSagi merupakan ritual pengungkapan rasa syukur atas keberhasilan panen kepada Tuhan YME. Dalam praktiknya Dero-Sagi memiliki dua fungsi yakni fungsi sosial dan fungsi transendental. Tulisan ini bermaksud mengupas kedua fungsi tersebut dengan menggunakan pendekatan kualitatif dan deskriptif. Selain itu, tulisan ini juga bermaksud mengungkapkan komposisi skematik lisan dalam tuturan lisan pertunjukan Dero-Sagi.
\end{abstract}

Kata Kunci: Tradisi lisan, Fungsi Sosial, dan Komposisi Skematik Lisan

\begin{abstract}
In the latest decade, the issue of marginalization of local culture (oral tradition) by the global culture is intensively discussed by social scientists. This paper aims to show how the local communities in Bajawa district, East Nusa Tenggara, actively maintain their Dero-Sagi ritual, an oral tradition, from the onslaught of globalization and local tradition marginalization. DeroSagi ritual is a ritual to show gratitude to the creator for the success of the harvest. In practice, Dero-Sagi ritual has two functions, namely social and transcendental functions. In this paper, the two functions are elaborated using qualitative and descriptive approaches. In addition, this paper also describe the oral schematic composition in Dero-Sagi ritual's oral speech.
\end{abstract}

Keywords: oral tradition, ritual function, schematic composition 


\section{Pendahuluan}

Masyarakat yang memiliki tradisi bercocoktanam biasanya memiliki kebudayaan yang lebih kompleks jika dibandingkan dengan masyarakat yang tidak bergantung pada budaya bercocoktanam. Salah satu contoh masyarakat dengan budaya bercocok tanam itu adalah masyarakat Bajawa di kabupaten Ngada, Flores, Nusa Tenggara Timur.Kabupaten Ngada berada di jantung pulau Flores dengan ibukota kabupaten adalah Bajawa. Luas wilayahnya 1.621 km2 dan jumlah penduduknya lebih kurang 142.254 jiwa dan memiliki tiga suku besar yakni suku Nagekeo, Bajawa, dan suku Riung. (http://wwwwikipedia.org/wiki/Bajawa_(kota), pukul 20.53. Minggu, 28 Agustus 2016). Pada tahun 2005 penduduk Ngada, Bajawa menurut hasil penelitian Schröter (2005: 318-319) masih berjumlah 60.000 jiwa. Kabupaten yang terletak di jantung Flores ini sebagian besar penduduknya menetap di bagianselatan dan tengah wilayah tersebut; merupakan salah satu kepulauan Sunda Lesser di Nusa Tenggara Timur yang menghadap ke Laut Sawu di sebelah selatan dan menghadap ke laut Flores di sebelah Utara serta berada di ketinggian 1000 meter dari permukaan laut (altitude). Beberapa perkampungannya menurut Susan masih terisolasi dan hanya dapat dijangkau dengan jalan kaki. Sumber mata pencarian penduduk sebagian masih bergantung pada pertanian, peternakan seperti, babi, kambing, anjing, kuda, kerbau, dan pertenunan terutama pada kaum perempuan. Molnar (2000:28) menjelaskan istilah Ngada sesungguhnya berasal dari bentukan kolonial Belanda yang masuk ke wilayah itu pada tahun 1907 di bawah pimpinan Kapten Christoffel.

Nama Ngada berasal dari salah satu tujuh klan terbesar yang terdapat di wilayah tersebut dan menurut mitos nenek moyang mereka telah melakukan perjalanan yang jauh dari tempat yang disebut dengan istilah [ри’u zili giu gema] 'tempat yang gelap gulita'. Dalam syair adat yang dinyanyikan [su'i uwi] disebutkan bahwa tempat yang jauh itu mengacu ke sebuah negeri bernama SinaOne 'Negeri Cina".Penjelasan mengenai asal mula nama Ngada pernah pula ditelusuri oleh seorang antropolog yang bernama Paul Arndt, SVD (1929). Ia menjelaskan bahwa istilah Ngada asalnya adalah Nad'a lalu berubah menjadi Nagdha, kemudian Nga'da dan akhirnya Ngada karena lebih mudah diucapkan oleh lidah generasi muda Ngada saatmereka mempromosikan daerah dan etniknya kepada turis yang berkunjung. Selanjutnya (Piskaty 1964; dalam Scrhöter (2005:319) menjelaskan pula bahwa sejak tahun 1910-an daerah ini sudah menjadi target misionaris dibawah kelompok SVD (SocietasVerbiDivini) dan saat ini hampir seratus persen penduduknya memeluk agama 
Katolik.

Salah satu tradisi lisan yang masih hidup dalam masyarakat Bajawa adalah tradisi Dero-Sagi. Dero-Sagi merupakan ekspresi pengungkapan rasa syukur kepada Tuhan atas keberhasilan panen. Ekspresi pengungkapan rasa syukur atas keberhasilan panen ini berkaitan dengan konsep kesuburan (fertility cult) yang tumbuh dan berkembang dalam masyarakat agraris. Konsep kesuburan ini biasanya dikaitkan dengan kepercayaan dan keyakinan kepada Dewi Ibu (MotherGoddes) yakni suatu unsur kebudayaan yang sudah tua dan sudah dianut oleh berbagai kebudayaan di dunia sejak zaman Batu Tua Akhir (Upper Palaeolithic), khusus di daerah Eropa Timur dan Tengah, Dewi (2011:219).Konsep ini awalnya dianut oleh masyarakat pendukung kebudayaan Gravettian, James (1961: 13-20), dan Santiko, (1977:56). Konsep pemujaan Dewi Ibu ini juga dianut oleh masyarakat-maysarakat agraris lainnya di dunia sebagaimana yang kita temukan di Indonesia dan juga di negara agraris lainnya seperti Thailand, Myamar, dan India, terutama yang masih menjalankan tradisi bertanam padi di sawah.

Penghormatan kepada Dewi Ibu dalam beberapa kebudayaan memiliki wujud dan bentuk ekspresi yang beragam tetapi hakikatnya sama yakni pengungkapan rasa syukur atas panen yang berlimpah. Tradisi ini dalam kebudayaan Jawa menurut Santiko (1977: 57-58) identik dengan pemujaan kepada Dewi Sri atau Dewi Padi; Nyi Pohaci Sangiang Sri dalam masyarakat Sunda. Tradisi lisan yang memuat kisah pemujaan kepada Dewi Sri di Jawa dapat dilihat dalam Babad Ila-Ila, SriSadana dalam pertunjukan Kentrung, Banyuwangi. Di Jawa Barat kisah-kisah Dewi Ibu ini disampaikan dalam cerita lisan maupun yang sudah diterbitkan, Holil, (2011:241). Di Ngada, Bajawa tradisi pengungkapan rasa syukur atas keberhasilan panen ini disebut dengan Dero-Sagi. DeroSagi biasanya diadakan pada saat pesta tahun baru [Reba] orang Ngada, Bajawa. RitualDero-Sagi ini juga berkaitan dengan penghargaan terhadap tumbuh-tumbuhan yang dibutuhkan oleh manusia seperti padi, jagung, sorgum, dan tanaman lainnya yang dikaitkan dengan pengorbanan seorang anak laki-laki.

\section{Pembahasan}

Penelitian tradisi lisan, memerlukan kerja lapangan karena data primer yang tersedia umumnya terdapat dalam ingatan para penutur tersebut. Hal ini senada dengan pandangan Lord (1976) yang menyampaikan bahwa kreasi lisan tercipta ketika dipentaskan atau dipertunjukkan. Dengan demikian maka sumber utama kajian tradisi lisan adalah penutur, pembawa, termasuk di sini nara sumber pemilik tradisi 
lisan yang diteliti. Pementasan, pertunjukan, ritual, atau peragaan menjadi kata kunci dalam hal ini. Datadiperoleh dari nara sumber kunci yang masih hidup; atau merupakan living traditions, ingatan kolektif yang tersimpan dalam masyarakat, dan sastra tersebut (memory traditions) seperti tetua adat, pelaku tradisi lisan (performers), dan anggota masyarakat pemilik tradis lisan. Selain data primer terdapat juga data sekunder yakni keterangan-keterangan yang diperlukan untuk mendukung data primer. Data sekunder itu mencakup pandangan pendukung tradisi lisan, seperti dari segi pencerita, pendengar atau penonton, tokoh masyarakat, pewaris tradisi lisan, dan ekspresi pencerita saat pertunjukan dilakukan, perlengkapan yang mendukung suatu pertunjukan lisan. Mengingat fenomena di atas, Sweeney (1972:65) menggambarkan lima komponen penting yang harus dilakukan oleh seorang peneliti tradisi lisan ketika ke lapangan yakni findinginformants (menemukan informan); dealing with informants (mufakat dengan nara sumber); recording (perekaman); interviewing (wawancara); dan transcription (transkripsi).

Tradisi lisan, dalam berbagai bentuknya sangat kompleks yang mencakup tidak hanya cerita lisan, mitos, legenda, dan dongeng melainkan juga merangkumi berbagai hal yang menyangkuttradisi (costume) komunitas pemiliknya, misalnya kearifan lokal (local wisdom), sistem nilai, ritual, sastralisan, sejarah, hukum, adat, pengobatan, sistem kepercayaan (religi), astrologi, dan berbagai hasil seni ${ }^{1}$. Perlupula diingat bahwa sebagai titik tolak penelitian, tradisi lisan itu sendiri dapat dilihat sebagai suatu peristiwa budaya atau sebagai suatu bentuk kebudayaan yang diciptakan kembali (invented culture) $)^{1}$ untuk dimanfaatkan, dikembangkan, dan direvitalisasi, atau sebagai suatu bentuk kebudayaan yang karena suatu alasan tertentu perlu dijaga dari kepunahannya. Komunitas pemilik dan atau pendukung sastra menjadi unsur penting yang harus dilihat dalam kehadiran tradisi lisan bersangkutan.

Dalam masyarakat lisan, di samping bahasa sehari-hari, dikembangkan pula satu bentuk bahasa yang disebut dengan "bentuk istimewa", yaitu bahasa yang menggunakan aliterasi, asonansi, irama khusus, serta formula dan bentuk terikat lainnya. Fungsi bentuk istimewa sangat praktis, yaitu melestarikan ilmu pengetahuan dalam budaya lisan. Pola-pola pengingat membolehkan satuan-satuan ilmu mudah diingat (Sweeney 1987:202). Akan tetapi berkembangnya bentuk istimewa ini dapat dipahami hanya dalam interaksinya dengan bahasa seharihari, karena bentuk tersebut memanfaatkan lalu "mengistimewakan" berbagai ciri bahasa

1 Hobsbaoum, Invented Culture, 1986 
sehari-hari itu. Lord (1976:67) menyebutnya dengan formula yakni kata atau sekelompok kata yang tetap bentuknya.

\section{Dero}

Dero-Sagi adalah tarian adat suku Bajawa yang dilakukan pada acara pesta panen sebagai ungkapan rasa syukur kepada Tuhandan leluhur atas keberhasilan panen yang diperoleh. Pertunjukan atau ritual Dero-Sagi terbagi dalam dua bagian. Bagian pertama adalah pertunjukan Dero yakni seluruh penari baik laki-laki maupun perempuan akan menyanyi dalam formasi lingkaran. Gerakan membentuk lingkaran ini merupakan simbol keharmonisan dan kebersamaan sebagai salah satu ciri dari masyarakat lisan (Ong, 1983:43). Dalam formasi lingkaran ini para pemuda dan pemudi akan bernyanyi bersama dan pada bagian tertentu mereka akan bernyanyi bersahutan antara kelompok laki-laki dan perempuan. Nyanyian itu akan dipandu oleh dua orang laki-laki yang berdiri di tengah lingkaran. Keduanya akan bergerak dalam lingkaran dan menghentakan kaki sebagai isyarat gerakan. Setiap gerakan yang mereka lakukan akan akan diikuti oleh semua penaridengan bernyanyi dan berpegangan tangan dalam lingkaran. Pada masa lalu, para penari akan bernyanyi mengelilingi lingkaran dan api unggun. Kedua orang yang berada di tengah lingkaran juga berfungsi sebagai pemimpin masing-masing kelompok untuk saling berbalas pantun dan syair dalam bahasa daerah Bajawa. Isi syair yang mereka nyanyikan itu umumnya berisi sindiran kepada masing-masing kelompok perempuan dan laki-laki. Masing-masing kelompok akan mendaraskan syair yang menggambarkan ke-lebihan dan kekurangan laki-laki dan perempuan seperti yang telah disebutkan di bagian atas.

Pada pertunjukan Dero ada syair yang dinyanyikan yang disebut dengan istilah teke. Teke yang dinyanyikan dibedakan atas dua bagian yaitu bagian pertama disebut Dhozo Enga (syair yang dinyanyikan oleh penyanyi solo) dan bagian kedua disebut Ana pata (syair yang dinyanyikan oleh kelompok atau kur). Pada bagian kedua ini, syair-nya sedikit berbeda dengan bagian pertama. Seniman yang berperan mengatur jalannya pertunjukan juga sudah diganti. Mereka adalah tiga laki-laki yang biasanya telah berumur antara 50 sampai 70 tahun (dalam rekaman semua diperankan oleh pemuda dan pemudi). Ketiga lelaki yang berada di tengah lingkaran itu berfungsi sebagai pengendali tempo dan keselarasan gerak para penari. Mereka akan bergantian menyanyikan syair secara solo dan membalasnya dalam bagian Ana Pata. Nyanyian bersahutan selanjutnya dilakukan silih berganti seperti semula hingga berakhirnya pendarasan Teke. Berikut ini adalah syair-syair yang dinyanyikan pada 
bagian Teke.

\section{Solo 1:}

Dhozo Enga:

E....e...e ine..

Ai manga mona, manga mona noe oe ine

Ai mona mona mona oga...

Refrein:

Ana Pata:

Ine oe dheo kami tua...dheo kami tua

Ine oe pati kami manu...pati kami manu

Kami keze mona ko pau

Dhozo Enga:

Ema o...e...ae..

Wali sanga wiwi lele mo'o dhizi ema

o...e...ae...

Wali sanga wiwi lele mo'o dhizi ema o...e...ae.. Ai mona mona moko nga'o
Solo 1

Dhozo Enga:

E..e...e ine...

Ai manga mona..manga mona noe oe ine(kalimat seruan).

Ai mona mona mona oga..

Refrein:

Ana Pata

Bawakan kami tuak, bawakan kami tuak Berikan kami ayam, berikan kami ayam

Kami tunggu tidak lari

\section{Solo 2:}

Dhozo Enga

Ema o...e..ae..

(kalimat seruan)

Tambah satu kalimat, dengar baik-baik

(Tambah satu kalimat)

dengar baik-baik

Ai mona mona moko nga'o

(kalimat seruan)

\section{Komposisi Formulaik Lisan dalam Syair Dero-Sagi}

Syair [teke]dalam ritual Dero-Sagi memiliki struktur formulaik lisan yang berulang. Pengulangan itu bisa berbentuk pengulangan setengah barismaupun pengulangan sepenuh baris. Komposisi formulaik lisan ini menjadi ciri dalam komunikasi lisan sebagaimana yang disampaikan oleh Lord (1976), Ong (1983), dan Sweeney (1987). Adapun pengulangan separuh baris dalam syair Dero-Sagi dapat dilihat pada contoh teks pada bait pertama berikut ini.
[Ine oe dheo kami tua.. dheo kami tua]

[Ine oe pati kami manu...pati kami manu]

Pengulangan seluruh baris terdapat dalam contoh larik di bawah ini.

[wali sanga wiwi lele mo'o dhizi ema]

wali sangawiwi lelemo'o dhizi ema]. 
Isi syair [teke] dalam pertunjukan komposisi formulaik lisan sepenuh baris juga Dero-Sagi juga memuat harapan kepada pencipta agar hujan turun dan kesuburan pada tumbuhan.Pada bagian syair yang mengandung harapan kesuburan itu dapat ditemukan terutama pada bagian syair EngaLewadan Ana Pata, seperti contoh teks dalam tabel di bawah terutama yang ditandai dengan garis di bawah.

\begin{tabular}{|c|c|}
\hline Bahasa Bajawa & Bahasa Indonesia \\
\hline $\begin{array}{l}\text { Enga Lewa: } \\
\text { Enga uza o enga o uza } \\
\text { Mai wae o mai o wae } \\
\text { O...ea...ea...oe... } \\
\text { O...ea...ea...oe... }\end{array}$ & $\begin{array}{l}\text { Panggil panjang } \\
\text { Panggil hujan...panggil o...hujan turunlah } \\
\text { air...turunlaho ...air } \\
\text { O...ea...ea...oe... } \\
\text { O...ea...ea...oe... }\end{array}$ \\
\hline $\begin{array}{l}\text { Enga Bhoko: } \\
\text { Enga uza uza mai wae }\end{array}$ & $\begin{array}{l}\text { Panggil pendek } \\
\text { Panggi hujan...turunlah hujan }\end{array}$ \\
\hline $\begin{array}{l}\text { Ana Pata: } \\
\text { Enga uza imu mai wae } \\
\text { Wae o...ea...oe... } \\
\text { Waku wae tua-tua e } \\
\text { o...ea...o...ea...o...ea } \\
\text { (diulang lagi dari bagian Enga Bhoko) }\end{array}$ & $\begin{array}{l}\text { Anak Syair: } \\
\text { Panggil hujan...datanglah air o...ea...oe... } \\
\text { Turunlah air hujan yang deras } \\
\text { o..eea..o...ea..o...e... } \\
\text { (diulang lagi dari bagian Enga Bhoko) }\end{array}$ \\
\hline 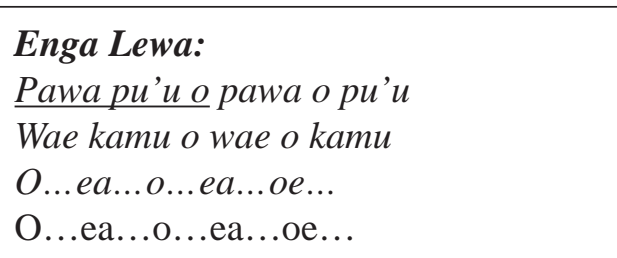 & $\begin{array}{l}\text { Panggil panjang } \\
\text { Siram dari akar-akarnya } \\
\text { Air membasahi akar o...air o...akar } \\
\text { O...ea...o...ea...oe } \\
\text { O...ea.......ea...oe }\end{array}$ \\
\hline $\begin{array}{l}\text { Enga Bhoko: } \\
\text { Pawa pu'u-pu'u wae kamu }\end{array}$ & $\begin{array}{l}\text { Panggil pendek: } \\
\text { Siram dari akar-akarnya }\end{array}$ \\
\hline $\begin{array}{l}\text { Ana Pata: } \\
\text { Pawa pu'u imu wae kamu } \\
\text { Kamu o...ea...oe... } \\
\text { Waku wae tua-tua e } \\
\text { Ea o...ea...o...ea...o...ea } \\
\text { (di ulang lagi dari bagian Enga Bhoko) }\end{array}$ & $\begin{array}{l}\text { Anak syair: } \\
\text { Siram dari akar-akarnya } \\
\text { Akar o...ea...oe... } \\
\text { Turunlah air hujan yang deras } \\
\text { ao...ea...o...ea...e } \\
\text { (di ulang lagi dari bagian Enga } \\
\text { Bhoko) }\end{array}$ \\
\hline $\begin{array}{l}\text { Enga Lewa: } \\
\text { Lobo mara o lobo o mara } \\
\text { Rilo ralo o rilo o ralo } \\
\text { O...ea ...o...e } a \text {...oe... }\end{array}$ & $\begin{array}{l}\text { Panggil Panjang: } \\
\text { Berikanlah pertumbuhan padi dan jagung } \\
\text { Sehingga menjadi subur } \\
\text { O...ea...o..ea ...o } \\
\text { O...ea...o...ea... }\end{array}$ \\
\hline $\begin{array}{l}\text { Enga Bhoko: } \\
\text { Lobo mara-mara rilo ralo }\end{array}$ & $\begin{array}{l}\text { Panggil Pendek: } \\
\text { Berikanlah pertumbuhan padi dan jagung }\end{array}$ \\
\hline
\end{tabular}




\begin{tabular}{|c|c|}
\hline $\begin{array}{l}\text { Ana Pata: } \\
\text { Lobo mara imu rilo raloRalo o...ea...oe... } \\
\text { Waku wae tua-tua e } \\
\text { Ea......ea......ea... } \\
\text { Ea.......еа......ea }\end{array}$ & $\begin{array}{l}\text { Anak Syair: } \\
\text { Berikanlah pertumbuhan padi dan jagung } \\
\text { sehingga menjadi subur } \\
\text { Menjadi subur } \\
\text { o...ea...oe... } \\
\text { Turunlah air hujan yang deras e... }\end{array}$ \\
\hline $\begin{array}{l}\text { Enga Lewa: } \\
\text { Wunu mara o wunu o mara } \\
\text { Debha dere o debha o dere } \\
\text { O...ea...o...ea...oe... } \\
\text { O...ea...o...ea...oe... } \\
\text { Enga Bhoko: } \\
\text { Wunu mara, mara debha dere }\end{array}$ & $\begin{array}{l}\text { Panggil Panjang } \\
\text { Bertambah besar o bertambah besar } \\
\text { Bertambah tinggi o bertambah tinggi } \\
\text { O...ea...o...ea...o } \\
\text { O..eea...o...ea...oe } \\
\text { Panggil Pendek: } \\
\text { Bertambah besar dan tinggi }\end{array}$ \\
\hline $\begin{array}{l}\text { Ana Pata: } \\
\text { Wunu mara imu debha dere } \\
\text { Dere o...ea..oe... } \\
\text { Waku wae tua tua e... } \\
\text { Ea o...ea...o...ea..o... } \\
\text { Ea } \\
\text { о...ea...o...ea..o... }\end{array}$ & $\begin{array}{l}\text { Anak Syair: } \\
\text { Bertambah besar dan tinggi } \\
\text { Tinggi o...ea..oe... } \\
\text { Turunlah air hujan yang deras e... } \\
\text { Ea...ea...o...ea..o } \\
\text { Eao...ea...o...ea... }\end{array}$ \\
\hline $\begin{array}{l}\text { Enga Lewa: } \\
\text { Sege ngere o sege o ngere } \\
\text { Wole lege o wole o lege } \\
\text { O ea...o..ea..oe... } \\
\text { O ea...o..ea..oe... } \\
\text { Enga Bhoko } \\
\text { Sege ngere, ngere wole lege } \\
\text { Ana Pata: } \\
\text { Sege ngere imu wole lege } \\
\text { Lege o ea oe... } \\
\text { Waku wae tua tua e... } \\
\text { Ea } \\
\text { o...ea...o...ea...o...e } \\
\text { Eo...ea...o...ea...o }\end{array}$ & $\begin{array}{l}\text { Panggil Panjang: } \\
\text { Mayangnya bertambah besar o mayang o besar } \\
\text { Mayangnya merunduk sampai di tanah } \\
\text { O ea...o..ea..oe... } \\
\text { O ea...o.ea..oe... } \\
\text { Panggil Pendek } \\
\text { Mayangnya bertambah besar hingga merunduk } \\
\text { sampai di tanah } \\
\text { Anak Syair } \\
\text { Mayangnya bertambah besar hingga merunduk } \\
\text { sampai di tanah } \\
\text { Merunduk o ea oe... } \\
\text { Turunlah air hujan yang deras e..ea } \\
\text { Ea ..o...ea...o...ea...o }\end{array}$ \\
\hline $\begin{array}{l}\text { Enga Lewa: } \\
\text { Ngere wea o ngere o wea } \\
\text { Pae te'a o pae o te'a } \\
\text { O ea..o..ea ..oe... } \\
\text { O ea..o..ea ..oe... } \\
\text { Enga Bhoko: } \\
\text { Ngere wea, wea pae te'a } \\
\text { Ana Pata: } \\
\text { Ngere wea imu pae te'a } \\
\text { Te'a o..ea..oe.. } \\
\text { Waku wae tua tua e... } \\
\text { Ea...ea...o...ea...o...e }\end{array}$ & $\begin{array}{l}\text { Panggil Panjang: } \\
\text { Menguning bulir padi o } \\
\text { menguning o bulir padi } \\
\text { Berkilauan bagaikan emas o berkialaun } \\
\text { o bagaikan emas } \\
\text { Oea..o..ea ..oe... } \\
\text { Oea..o..ea ..oe... } \\
\text { Panggil Pendek: } \\
\text { Menguning bulir-bulir padi dan berkilauan } \\
\text { bagaikan emas } \\
\text { Ea..ea...o...ea...o...e } \\
\text { a..o...ea...o...ea...o...ea }\end{array}$ \\
\hline
\end{tabular}




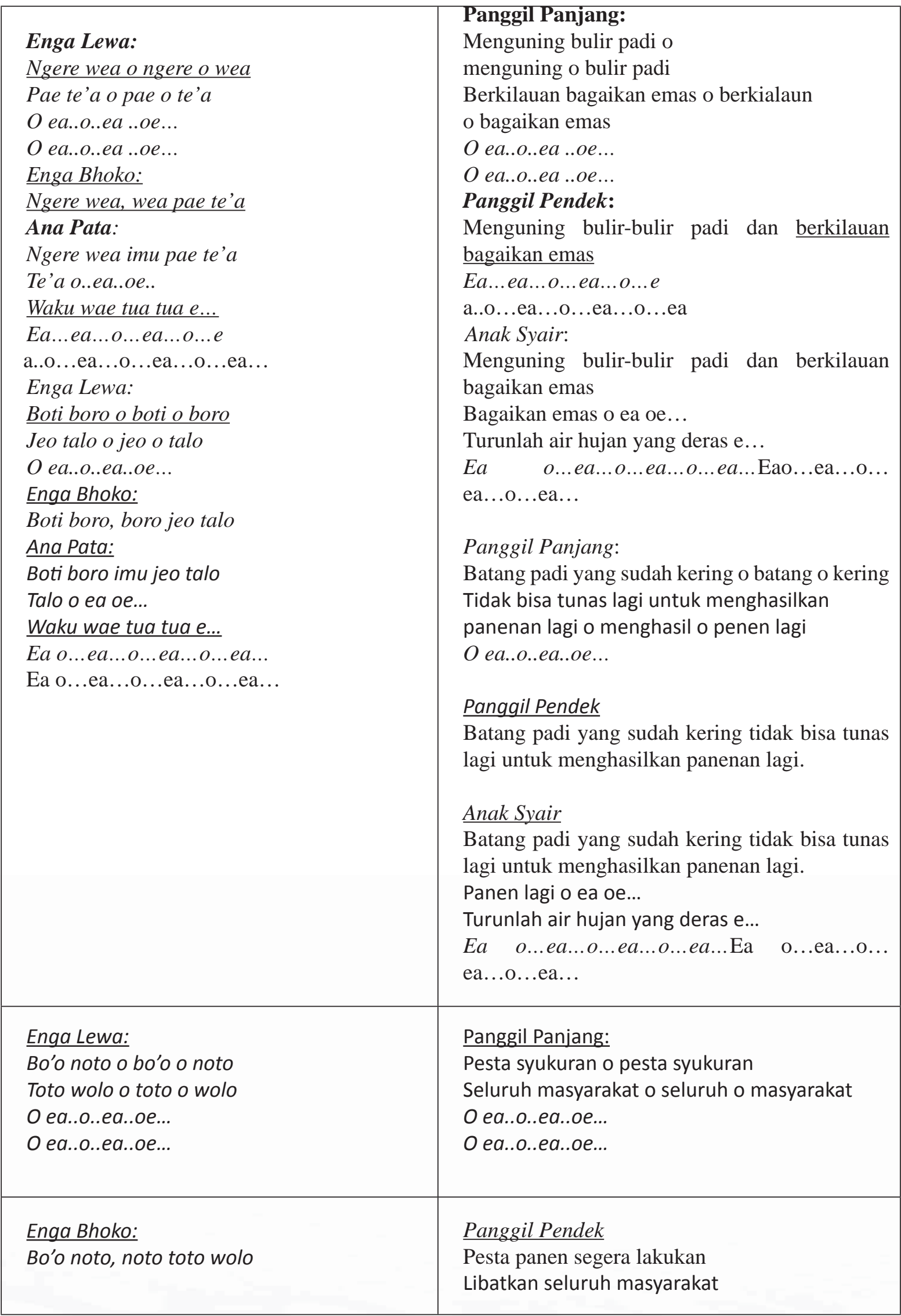


Sagi

Pertunjukan kedua disebut Sagi yakni tinju adat adat yang dimainkan oleh lakilaki. Pertandingan tinju adat beraawal dari mitos kesuburan yang terdapat dalam cerita lisan etnis Ngada, Bajawa. Berdasarkan cerita lisan yang hidup di tengah masyarakat Bajawa disampaikan bahwa dahulu kala tanah di daerah itu masih gersang dan tanaman padi, jagung, dan sorgum belum ada. Kekeringan yang melanda di daerah itu telah menyebabkan kelaparan dan penderitaan yang panjang. Termasuk satu keluarga yang memiliki anak laki-laki dan perempuan. Suatu malam ayah dari sang anak bermimpi. Dalam mimpinya ia didatangi oleh seorang lelaki tua. Lelaki tua itu menyarankan pada si ayah agar mengorbankan anak laki-lakinya dengan jalan mencincang tubuh anaknya itu dan kemudian ditanamkan di setiap sudut ladangnya. Perbuatan itu diperlukan untuk mendapatkan kesuburan dan menghilangkan kekeringan yang melanda ladangnya. Si Ayah kemudian menyampaikan mimpinya itu kepada anak laki-lakinya yang kemudian menyetujui nasehat orang tua dalam mimpi tersebut. Singkat kata, anak laki-laki tersebut bersedia dikorbankan dan pengorbanannya itu kemudian memberi hasil. Tanah ladang mereka kemudian menjadi subur dan di setiap sudut ladang yang ditanami jasad anak tersebut kemudian muncullah berbagai tumbuhan termasuk padi.
Tinju adat [Sagi] ini melibatkan dua orang petinju dari masing-masing kelompok atau kampung yang dipilih sebagai wakil. Pada saat bertarung, para petinju akan dibekali dengan sarung tinju dari tumbuhan kering. Masing-masing petinju akan beradu dengan bersemangat dan laga ini kadang menjadi ajang bagi para pemuda untuk memperlihatkan keperkasaan mereka sebagai laki-lakidi depan para gadis-gadis yang menonton.

Darah yang menetes dari tubuh para pemuda dalam tinju adat $[\mathrm{Sagi}]$ juga dapat dibaca sebagai simbol pengorbanan anak laki-laki (ritus inisiasi). Finnegan (1979) menyebutkan bahwa ritual tradisi lisan itu memiliki fungsi sakral bagi setiap pembawa kebudayaan tersebut. Nilai sakral dari ritual Sagi ini dapat dilihat dari rituspengorbanan darah anak laki tadi. Selain itu, ritus pengorbanan ini juga dapat dibaca sebagai ritus pengorbana dan penghormatan kepada Dewi Ibu (mother Goddes). Penghormatan kepada Dewi Ibu representasi dari mitologi kesuburan.Darah anak lakilaki yang dikorbankan dianggap lebih sakral jika dibandingkan dengan darah anak perempuan. Oleh sebab itulah darah laki-laki anak laki-laki dalam tinju adat [Sagi] yang dipersembahkan kepada Dewi Ibu atau bumi (MotherGoddes). Hal ini sangat berbeda dengan mitos kesuburan yang dikenal di Jawa dan Bali. Mitos kesuburan di Jawa dan Bali 
justru meyakni bahwa asal mula padi dan tumbuhan berasal dari penjelmaan seorang perempuan (Dewi Sri). Namun, dibalik perbedaan itu masih terdapat persamaan motif cerita yakni kedua cerita sama-sama memiliki motif pengorbanan (sacrified motif) dan motif penjelmaan(transformationmotif); manusia menjelma tumbuhan.

Persembahan darah anak laki juga dapat dimaknai sebagai penghargaan kepada budaya patriakhi. Meskipun dalam sistem pewarisan dan hak atas tanah, tempat tinggal, harta dari nenek moyang yang sudah meninggal dalam etnis Ngada, Bajawa justru diwariskan secara matrilineal dari ibu kepada anak perempuan. Hanya benda-benda pribadi milik ayah yang dapat diwariskan kepada anak laki-lakinya (Schröter, 2005:322). Perubahan sistem pewarisan di Ngada yang semula patriarkhi dan kemudian berubah menjadi matrilini ini menurut Schröter, (2005:338) diakibatkan oleh beberapa faktor seperti faktor perdagangan, penaklukan, dan migrasi yang mampu mengubah struktur sosial, politik, dan perubahan ekonomi dalam sebuah masyarakat yang indegenous (asli) sekalipun.

Formasi penari dalam pertunjukan Sagi juga membentuk formasi yang berbeda saat pertunjukan Dero. Para penari memisahkan diri dari kelompok lingkaran besar yang semula terdapat dalam pertunjukan Dero. Kelompok perempuan menjadi penonton di pinggir dan kelompok pemuda membentuk dua kelompok. Kedua kelompok pemuda akan mempersiapkan masing-masing wakilnya untuk berlaga dalam adu tinju adat [Sagi]. Masing-masing kelompok petarung ini akan memegang sebilah tongkat panjang yang dihentakan pada bilah-bilah bambu yang diletakan di tanah. Bunyi-bunyian yang ditimbulkan oleh kayu dan bambu tadi berfungsi sebagai musik penyemangat dalam adu tinju adat yang berlangsung. Selain itu, tongkat dan bambu juga berfungi sebagai pembatas (ring) antara dua kelompok yang saling berhadapan di arena. Peran wasit dalam adu tinju adat ini dilakukan oleh seorang tetua adat yang mengontrol kejujuran dan sportifitas selama pertarungan berlangsung. Dan masingmasing petinju dilengkapi dengan sarung tinju yang berasal dari tumbuhan kering. Tidak jarang adu tinju adat ini menimbulkan semangat kompetisi dan tindakan emosional dari masig-masing petinju yang biasanya akan segera dilerai oleh wasit. Adapun sebelum Sagi berlangsung biasanya akan dinyanyikan syair [teke] yang berbunyi sebagai berikut.

Keso... he... he... he... kisa nata kita dia e... Dia kisa nata.

Kedhi-kedhi ana piko lau pubu e... Marikita meramai-riakan tinju adat ditengah kampung bersama para leluhur kita. 


\section{Waktu Pertunjukan dan Kostum Dero- Sagi}

Biasanya waktu pertunjukan dilakukan pada malam hari dan di lakukan di depan api unggun. Tetapi dalam rekaman untuk penelitian hal itu tidak dapat dilakukan karena perekaman diadakan di waktu siang.

Kostum yang digunakan oleh penari laki-laki terdiri atas kostum ikat kepala (lesu), kain adat (ragi), parang (sodi), selendang,dan tas (bere). Perempuan mengenakan pakaian adat (Kodo doi) dan kain adat (Nai doi), selendang, dan tas perempuan (Ripe oka). Penari perempuan juga memakai blus atau atasan yang berwarna hitam dan tanpa motif. Laki-laki menggunakan kemeja atau baju kaus sehari-hari.

Motif-motif kain tenun Bajawa yang indah dan menggunakan zat pewarna alami akan menjadi bawahan yang digunakan dalam pertunjukan Dero-Sagi. Beberapa motif yang muncul dalam kain tenun dari NTT ini adalah motif binatang seperti burung elang dan buaya. Selain itu juga terdapat motif binatang dan tumbuhan. Motif binatang seperti burung elang dan buaya ini biasanya dipakai oleh para bangsawan. Sedangkan orang biasa banyak menggunakan motif tumbuhan atau motif garis pada kain tenun yang mereka pakai.

\section{Fungsi Sosial dan Transendental}

\section{Dero-Sagi}

Sebagai masyarakat agraris, orang Bajawamemilikikonseppembagiankelompok sosial berdasarkan budaya bercocok tanam tersebut yang disebut dengan istilah rauzo. Selain mengenal pengelompokan sosial berdasarkan pekerjaan, masyarakat Bhajawa memiliki sistem kinshipyang terbagi atas tiga lapisan sosial yaknilapisan sosial paling atas adalah gà é méze, yang terbagi atas kelompok sosial panglima perang, tetua adat, dan pemimpin ritual adat. Lapisan sosial yang kedua adalah gà ékisa yang bermakna di tengah. Dan lapisan sosial yang ketiga adalah zo o atau hoo sebagai kelompok yang paling rendah, kecil atau yang termuda. (Schröter, 2004:323). Namun, lapisan sosial ini menjadi cair ketika mereka berkumpul dalam tarian Dero-Sagi yang mampu menerabas batas dan lapisan sosial ini.

Secara umum, ritual Dero-Sagi memiliki dua fungsi yakni pertama fungi sosial yang menjadi ajang bagi pemuda dan pemudi untuk saling menemukan pasangan dan jodohnya atau mengandung dimensi vertikal (sosial) dengan masyarakat komunal. Inilah saatnya untuk mengenal lebih dekat setiap anggota sosial dan komunal terutama bagi para pemuda dan gadis yang paling banyak terlibat dalam pertunjukan DeroSagi. Kedua adalah fungsi transendental sebagai ungkapan rasa syukur kepada sang 
pencipta yang telah memberikan kesuburan bagi pertanian mereka; melambangkan adanya relasi horizontal antara manusia dengan penciptanya.

Selain itu, dalam pertunjukan Sagi juga dapat dilihat fungsi ritual yang berkaitan dengan ritus inisiasi. Ritus inisiai ini direpsentasikan melalui tinju adat yang dilakukan oleh pemuda atau remaja lakilaki yang bertarung hingga mengucurkan darah dari tubuh mereka. Ritus inisiasi ini merupakan bagian dari pengalaman lokal masyarakat Ngada, Bajawa yang menurut Finnegan (1979:135--136) adalah hal yang penting dalam kajian tradisi lisan untuk melihat hubungan antara tradisi lisan dengan kepercayaan, agama, pengalaman, dan lambang-lambang khusus yang bersifat lokal. Demikian juga untuk melihat pertunjukan Dero-Sagi maka perlu memperhatikan hubungan antara kepercayaan, agama, pengalaman dan lambang-lambang yang bersifat lokal dalam masyarakat Bajawa. Ritus inisiasi ini juga dapat dilihat sebagai rangkaian upacara yang terdapat di masyarakat sejak manusia lahir hingga meninggal dianggap penting bagi pengusung budaya itu (Wiradnyana, 2010:152).

Fungsi sosial dan transendental dalam pertunjukan Dero-Sagi juga tereksplisit dalam syair [teke] yang mereka nyanyikan.Dalam pertunjukan Dero misalnya terdapat syair yang menggambarkan bagaimana pandangan laki-laki terhadap perempuan yang ideal dan sebaliknya begitu pula diungkapkan gambaran ideal seorang laki-laki dalam pandangan perempuan Bajawa.Adakalanya isi syair mengandung sindiran dan ejekan terhadap masing-masing lawan jenis. Berikut kutipan syair dalam ritual Dero-Sagi yang menggambarkan konsep ideal laki-laki dan perempuan dalam masyaakat Ngada, Bajawa.

\begin{tabular}{|c|c|}
\hline Bahasa Bajawa & $\begin{array}{c}\text { Bahasa } \\
\text { Indonesia }\end{array}$ \\
\hline $\begin{array}{l}\text { Laki-Laki } \\
\text { O weta e... lo kau da gaga } \\
\text { kami bula bhogo ngaLo } \\
\text { kau da modhe ghiri-ghole- } \\
\text { ghiri gho ( } 2 x) \\
\text { De zapa weta la'a lau mala } \\
\text { zogu } \\
\text { dheo taka lima kau da saza }\end{array}$ & $\begin{array}{l}\text { Laki-Laki } \\
\text { Adik mukamu } \\
\text { cantik sekalitapi } \\
\text { saya tidak } \\
\text { tertarik. } \\
\text { Muka kamu } \\
\text { begitu manistapi } \\
\text { tidak berarti di } \\
\text { mata saya }(2 \mathrm{x}) \\
\text { Karena di saat } \\
\text { pergi ke sawah } \\
\text { kamu tidak tahu } \\
\text { kerja }\end{array}$ \\
\hline $\begin{array}{l}\text { Laki-laki } \\
\text { Miu ta o'o fai } \\
\text { Mo tau dhoko su'u. }\end{array}$ & $\begin{array}{l}\text { Laki-Laki: } \\
\text { Kamu yang } \\
\text { perempuan } \\
\text { Jangan hanya } \\
\text { menenun kain } \\
\text { bunga } \\
\text { Tahu kerja } \\
\text { menganyam } \\
\text { Bisa gunakan } \\
\text { untuk junjung } \\
\text { dan jinjing }\end{array}$ \\
\hline
\end{tabular}




\begin{tabular}{|c|c|}
\hline $\begin{array}{l}\text { Perempuan } \\
\text { O nara e e kami ana halo } \\
\text { Nara tei dhato kami meza } \\
\text { me'a } \\
\text { Nara tei mema }\end{array}$ & $\begin{array}{l}\text { Perempuan } \\
\text { O saudara e e } \\
\text { kami anak yatim } \\
\text { piatu. } \\
\text { Saudara lihat } \\
\text { sendiri kami } \\
\text { tinggal sendiri } \\
\text { Saudara lihat } \\
\text { memang } \\
\text { sekarang }\end{array}$ \\
\hline $\begin{array}{l}\text { Laki-laki } \\
\text { Bu'e aja nee taa wola wea } \\
\text { Ta meza keka me'a. } \\
\text { Poa ou rita rita reku enga } \\
\text { enga nangi. } \\
\text { Kau ana ko sai. } \\
\text { Kau ana ko sai. } \\
\text { Nona raja dengan wolowea. }\end{array}$ & $\begin{array}{l}\text { Laki-Laki } \\
\text { Yang tinggal } \\
\text { rumah sendiri. } \\
\text { Pagi-pagi ou } \\
\text { menangis- } \\
\text { menangis } \\
\text { Sore panggil } \\
\text { menangis. Kau } \\
\text { siapa anak. } \\
\text { Kau siapa punya } \\
\text { anak. }\end{array}$ \\
\hline
\end{tabular}

Kecantikan seorang perempuan menurut laki-laki Ngada, Bajawa tidak bermakna jika perempuan itu tidak pandai dan terampil bekerja di sawah. Demikian juga ketampanan seorang laki-laki tidak ada gunanya jika dia pemalas dan tidak mampu bekerja di sawah. Konsep kecantikan dan ketampanan di Bajawa ternyata sangat berkaitan dengan keterampilan bekerja di sawah. Jadi, tidak semata bermodalkan tampang belaka karena ketrampilan bekerja terutama di sawahlah yang paling menentukan bagi laki-laki maupun perempuan untuk bisa dijadikan calon istri maupun suami. Hal ini sangat bertolak belakang dengan kosnep kecantikan masyarakat di perkotaan yang menilai kecantikan perempuan dari seberapa putih kulit perempuan atau laki-laki.

Dalam pertunjukan Dero-Sagi, kita juga menemukan semangat berkampung (komunalitas). Semangat berkampung atau komunalitas ( Ong, 1983 dan Sweeney 1987) adalah salah satu ciri dari masyarakat yang masih kuat orientasi lisannya sebagaimana yang diperlihatkan dalam pertunjukan Dero-Sagi ini. Semangat kebersamaan itu disimbolkan melalui gerakan melingkar. Pada masa dahulu gerakan melingkar ini bisanya dilaukan di depan api unggun tetapi sekarang tidak lagi dilakukan karena sudah ada listrik atau penerangan lainnya. 


\section{Simpulan}

Pertunjukan Dero-Sagi merupakan ritual pengungkapan rasa syukur atas keberhasilan panen dari masyarakat Ngada, Bajawa, Flores NTT. Tradisi pengungkapan rasa syukur terhadap keberhasilan panen ini merupakan representasi darispirit dan mitos kesuburan (fertility cult) kepada Dewi Ibu (The Mother God) yang sudah berlangsung ribuan tahun dalam budaya masyarakat agraris di Eropa danmasih dilaksanakan di beberapa wilayah dan budaya agraris di belahan dunia lainnya, termasuk di Indonesia dan Asia Tenggara.

Selain sebagaiungkapan rasa syukur, pertunjukan Dero-Sagi juga memiliki fungsi ritus inisiasi dalam bentuk persembahan darah pemuda (anak laki-laki) terutama dalam bagian pertunjukan Sagi 'tinju adat'. Selain menggambarkan ritus inisiasi.Ritual Dero-Sagi juga dapat dimaknai memiliki fungsi sosial dan fungsi transendental. Fungsi sosial terepresentasi dalam syair [teke] yang menggambarkan'dialog' antara kelompok pemuda dan pemudi yang saling berbalas lagu dan menelisik masing-masing pasangan yang akan dijadikan calon kekasih bahkan calon istri maupun suami.Fungsi transendental dalam ritual ini tergambar dalam syair yang mengandung ungkapan rasa syukur kepada Pencipta yang telah memberikan kesuburan dan keberlimpahan hasil panen. 


\section{Daftar Pustaka}

Dewi, Trisna Kumala Satya. 2011. "Dewi Sri Sebagai Mitos Kesuburan dan Realitanya dalam Masyarakat Jawa" dalam Teks, Naskah, dan Kelisanan Nusantara. Depok. Yayasan Pernaskahan Nusantara.

Finnegan,Ruth. 1977. Oral Poetry: Its Nature, Significance and Social Context. Cambridge: Cambridge University Press.

Holil, Munawar. 2011. "Sumber Lisan dan Tulis Upacara Seren Taun di Cigugur,Kabupaten Kunangan" dalam dalam Teks, Naskah, dan Kelisanan Nusantara. Depok. Yayasan Pernaskahan Nusantara.

Hobsbauwm,E.J dan T.O. Ranger. 1983. Invented of Tradition. Cambridge: University Press. James, E.O. 1961. Mother Goddes. London: Thames Hudson.

Lord, Albert B. 1976. The Singer of Tales. New York: Atheneum.

Molnar, Andrea Katalin.2000. Grand Chrildren of the Ga'é Ancestors; SocialOrganization and Cosmology Among the Hoga Sara of Flores. Leiden KITLV Press.

[Verhandelingen 185]

Piskaty, Kurt.1964. dalam Schroter, Susanne. 2005. Die Katholische Missionschule in Nusa Tenggara (Südost-Indonesien): ihregeschichtlicheEnfaltungundihreBedeutugfür die Missionsarbeit. St. Augustin/Siegburg:SteylerVerlag. [Studia Instituti Missiologici Societas Verbi Divini 5.]

Ong, Walter J. 1982. Orality and Literacy: The Technologizing of the Word. London and New York: Methuen.

Sweeney, Amin.1980. Authors and Audiences in Traditional Malay Literature. Berkeley: University of California.

1987. A Full Hearing: Orality And Literacy In The Malay World. Berkeley: University of California Press.

Santiko, Hariani. 1977.’Dewi Sri Unsur Pemujaan Kesuburan pada Mitos Padi” dalam Majalah Ilmu-Ilmu Sastra Indonesia (MISI). September 1977.Jilid VII. Nomor 3. Yogyakarta: Fakultas Sastra.

Schroter, Susanne. 2005. Red Cocks and Blakc Hens: Gendered Symbolism, Kinship and Social Pratice in The Ngada Higlands. Bijdragen tot de Taal-, Land-en Volkenkunde $161.2 / 32005$

Wiradnyana, Ketut. 2010. Legitimasi Kekuasaan Pada Budaya Nias: Padua penelitian Arkeologi dan Antropologi. Jakarta: Yayasan Pusta Obor Indonesia http://www.wikipedia.org/wiki/Bajawa_(kota), pukul 20.53. Minggu, 28 Agutus 2016 